(RESEARCH ARTICLE)

\title{
Biodegradation of polypropylene by bacterial isolates from the organs of a fish, Liza grandisquamis harvested from Ohiakwu estuary in Rivers State, Nigeria.
}

\author{
Lawrence Omunakwe Amadi * and Thomas Osahon Nosayame \\ Department of Microbiology, Faculty of Science, Rivers State University, P.M.B. 5080, Nkpolu-Oroworukwo, Port Harcourt, \\ Nigeria.
}

Publication history: Received on 12 August 2020; revised on 26 August 2020; accepted on 29 August 2020

Article DOI: https://doi.org/10.30574/wjarr.2020.7.2.0299

\begin{abstract}
Biodegradation of polypropylene (PP) by bacteria isolated from internal organs of mullet, Liza grandisquamis were assessed using gravimetric (weight loss) and Fourier transform infrared (FTIR) spectroscopy analyses. Bacterial isolates; Staphylococcus epidermidis (AE015931), Pseudomonas xiamenensis (MH734834), Bacillus licheniformis (AF478085), Klebsiella pneumoniae (MH021669), Bacillus lentus (AB021189) and Escherichia coli (KX609714) were screened for capacity to degrade PP, respectively. From the data obtained the degradation of PP occurred in the following order; Bacillus lentus $>$ B. licheniformis $>$ Staphylococcus epidermidis $>$ Klebsiella pneumoniae $>$ Escherichia coli overtime. However, further research would be needed to understand clearly the mechanism of biodegradation of PP and the applicability of these bacteria on related synthetic polymers. The standardized protocols for the biodegradation of PP are also required.
\end{abstract}

Keywords: Microplastic; Polypropylene; Mullet; Bacteria; FTIR spectroscopy

\section{Introduction}

The plastic debris at the sea surface consist of mainly polyethylene (PE), polypropylene (PP) and polystyrene (PS) because of their high surface-to-volume ratios $[1,2]$. The sorbent property, oleophilic, hydrophobic and high buoyancy of $\mathrm{PP}$, also have resulted in wide scale application for oil spill remediation programmes $[3,4]$. The occurrence of the five most abundant polymers in the environments have been reported to followed this order PE $>$ PP $>$ PVC $>$ PET $>$ PS due to global plastic demand and polymer density $[5,6,7]$.

The demand for PP alone was high with an estimated 25\% global consumption in 2012, and has broad range of applications such as in polymer blending processes, food, medical, beverage and automobile industries [8-11]. According to Proshad et al.[11] no harmful substances are found in foodstuffs packaged in PP containers and are therefore, considered safe for humans. Conversely, the use of PP has been shown to have different but harmful effects on various cell lines, based on the size and different concentrations in use, and that the interaction of microplastics with humans have capacity to produce different pathological conditions such as cytotoxicity, hypersensitivity, unwanted immune responses, and acute responses like haemolysis, thus representing a potential risk to human health [12,13].

Even though PP is a polyolefin/saturated polymer which is prone to oxidative degradation as PE, it differs from it by possessing a methyl substituent which makes it more resistant to microbial degradation. However, reports on degradability of PP by microbes focused exclusively on those derived from soil $[14,15]$ whereas majority of investigators concentrated on biodegraders of polymers from soil and sea/water sources exclusive of PP [8,16,17]. Such biodegrading bacteria of synthetic polymers have been reported to belong to several genera; Bacillus, Pseudomonas, Staphyolococcus,

\footnotetext{
* Corresponding author: Lawrence Omunakwe Amadi

Department of Microbiology, Faculty of Science, Rivers State University, P.M.B. 5080, Nkpolu-Oroworukwo, Port Harcourt, Nigeria. 
Acinetobacter, Brevibacillus, Comamonas, Microbacterium, Alcaligenes, etc., [8,17,18,19] whereas Pseudomonas and Vibrio were reported for PP [14,20].

Little or no research is focused on the degradation of PP by bacteria isolated from vertebrate sources such as fish. In spite of the massive accumulation of PP in the environment and putative human health problems there is paucity of literature on its biodegradation. Therefore, this study investigates the biodegradation of polypropylene by bacterial isolates from the organs of a fish, Liza grandisquamis harvested from Ohiakwu estuary in Rivers State, Nigeria.

\section{Material and methods}

\subsection{Source of bacteria}

The bacteria used for this work was obtained from those identified molecularly as part of a research project carried out at the Department of Microbiology, Rivers State University, Nkpolu-Oroworukwo, Port Harcourt.

\subsection{Identification of polypropylene (PP) and confirmation}

PP particles were sorted under a dissection microscope fitted with ocular lens and finally identified under a light microscope. The PP sample used was washed and left to dry at ambient temperature. It was confirmed using Fourier transform infrared (FTIR) spectroscopy with a single-element MCT detector. Cary 620-670 FTIR microscope, equipped with a GeATR crystal (Agilent Technologies) was used for the analysis and recorded directly with a spectral resolution of $8 \mathrm{~cm}^{-1}$, in the $4000-650 \mathrm{~cm}^{-1}$ spectral range.

\subsection{Biodegradation of PP by gravimetric (weight loss) analysis}

Microplastics isolated from the organic matter of the fish were weighed and aseptically transferred to nutrient broth medium and inoculated with isolates (hydrocarbon utilizing bacteria from Mullet) to determine biodegradability of plastic fragments. Control were maintained with plastic discs in the microbe-free medium. The removal of bacteria from the plastic surfaces was confirmed by microscopic examination. Different flasks were kept in a shaker for 30 days at room temperature. Then, the PP particles were collected, washed thoroughly using distilled water, shaded-dry and then weighed for final weight. The percentage degradation was determined by measurement of gravimetric weight loss using the formula:

$$
\text { Weight loss }(\%)=\quad \frac{(\text { Initial weight }- \text { Final weight })}{\text { Initial weight }} \times 100
$$

\subsection{Statistical analysis}

All the experiments were carried out in duplicates $(n=2)$ and the results are presented in mean value with standard deviation (Mean \pm SD). Duncan multiple test, two-way ANOVA and SPSS version 22 were used.

\section{Results and discussion}

Bacterial growth was initiated over a period of 5 days, attaching to the surface of polymer pellet, extended around it overtime. Some of the degradation effects are visible such as discolouration, loss of gloss and brittleness compared to the uninoculated whereas other chemical changes, such as bond scission and the formation of new functional groups were detected only with specific analyses. Previous exposure to the internal fish microcosm and size would have also contributed to enhancement of degradation [2,14,21] Furthermore, surface irregularities (increased ridges) on PP sheet depicted in Figure 1, after 2weeks of incubation suggests bacterial attack. Similar findings had been reported in literatures [22-25]. The deterioration/degradation was possible due to chain cleavage, leading to the formation of lowmolecular weight fragments (oligomers), dimers or monomers [26]. The degradation is due to the extra cellular enzymes secreted by the organism. These low molecular weight compounds are further utilised by the microbes as carbon and energy sources. Small oligomers may also diffuse into the organism and get assimilated. 


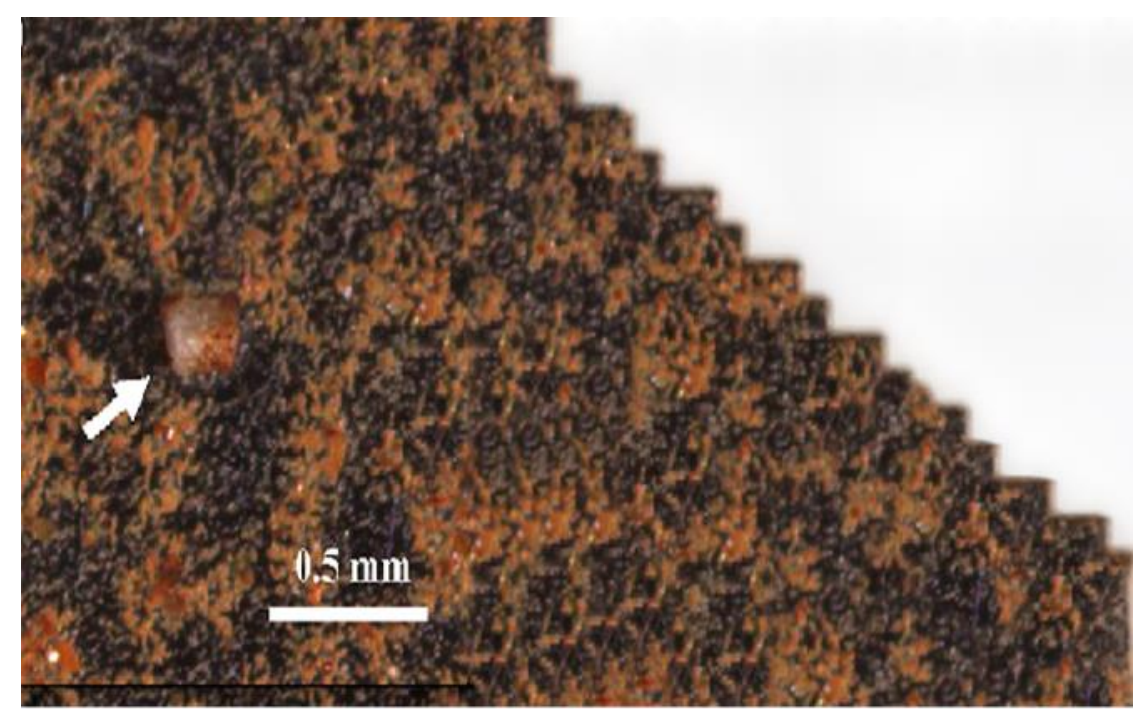

Figure 1 FTIR spectroscopy photograph of PP at storage/incubation.

After 5 days of incubation, biofilm was observed over the surface of polypropylene pellet and when the gravimetric (weight loss) analysis was done there was slight increase in weight. Then, the samples were kept for an extended incubation period until a significant difference in weight compared to initial weight was recorded. According to Cacciari et al. [14], PPs incubated with adapted communities of microbes under limited aerobiosis without preliminary chemical or physical treatment undergoes biodegradation [14]. The results indicated that $B$. lentus had the highest percentage weight loss, (i.e., colonized and utilized more PP as carbon source than others) followed by B. licheniformis and Staphylococcus epidermidis, Figure 2.

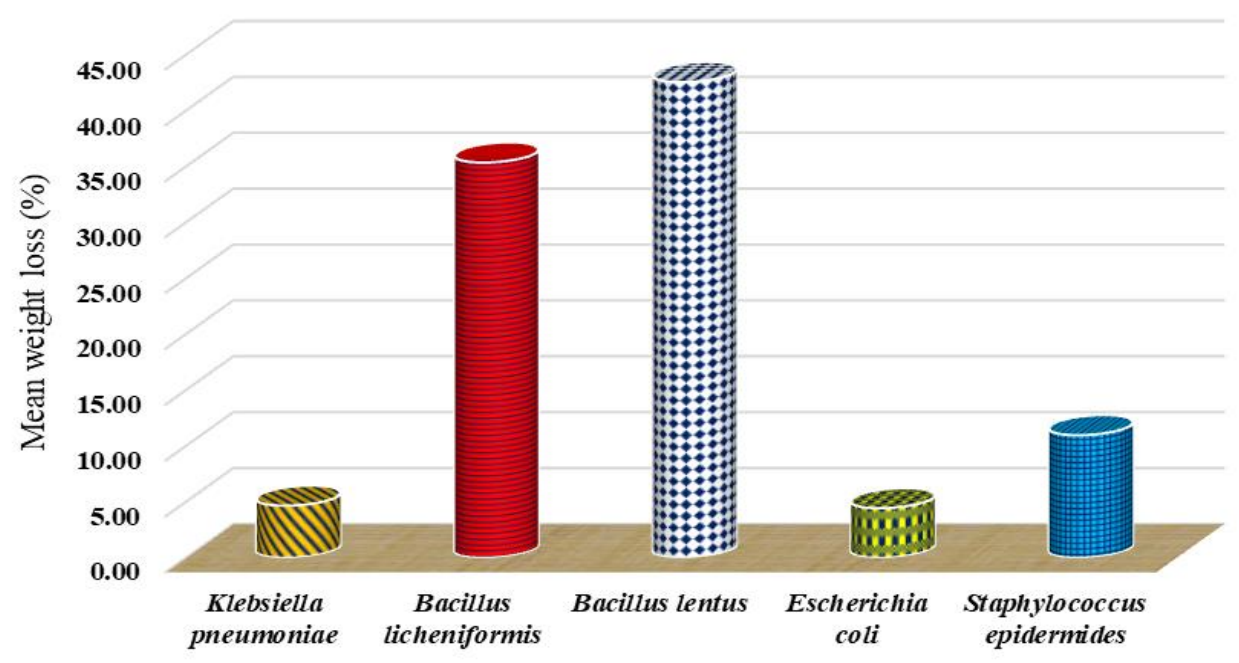

Figure 2 Gravimetric (weight loss) of PP due to bacterial degradation.

The FTIR spectrum of fraction (Fig. 3) showed -C-H stretch at 3000-2800 $\mathrm{cm}^{-1}$ (Alkane), $-\mathrm{C}-\mathrm{H}$ bend at $1470 \mathrm{~cm}^{-1}$ (Alkane) and $-\mathrm{CH}_{3}$ (Methyl) confirmed the hydrocarbon structure. In addition, both spectra (Fig. 4) at 1800-1665 $\mathrm{cm}^{-1}$ (Ketone) and at $1200-1000 \mathrm{~cm}^{-1}$ (Alcohol, ester) validates that certain limited oxyfunctionalization of carbon chain has occurred $[14,17,27]$. 


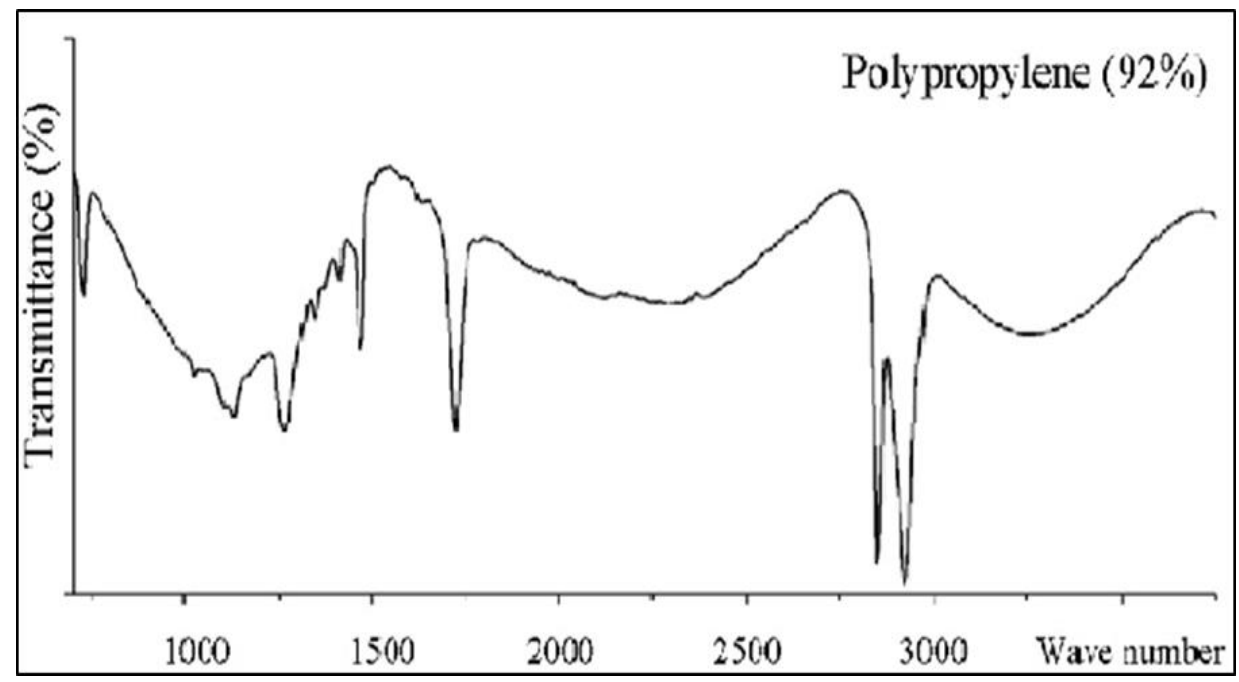

Figure 3 Fourier transform infrared (FTIR) spectra of Polypropylene overtime.

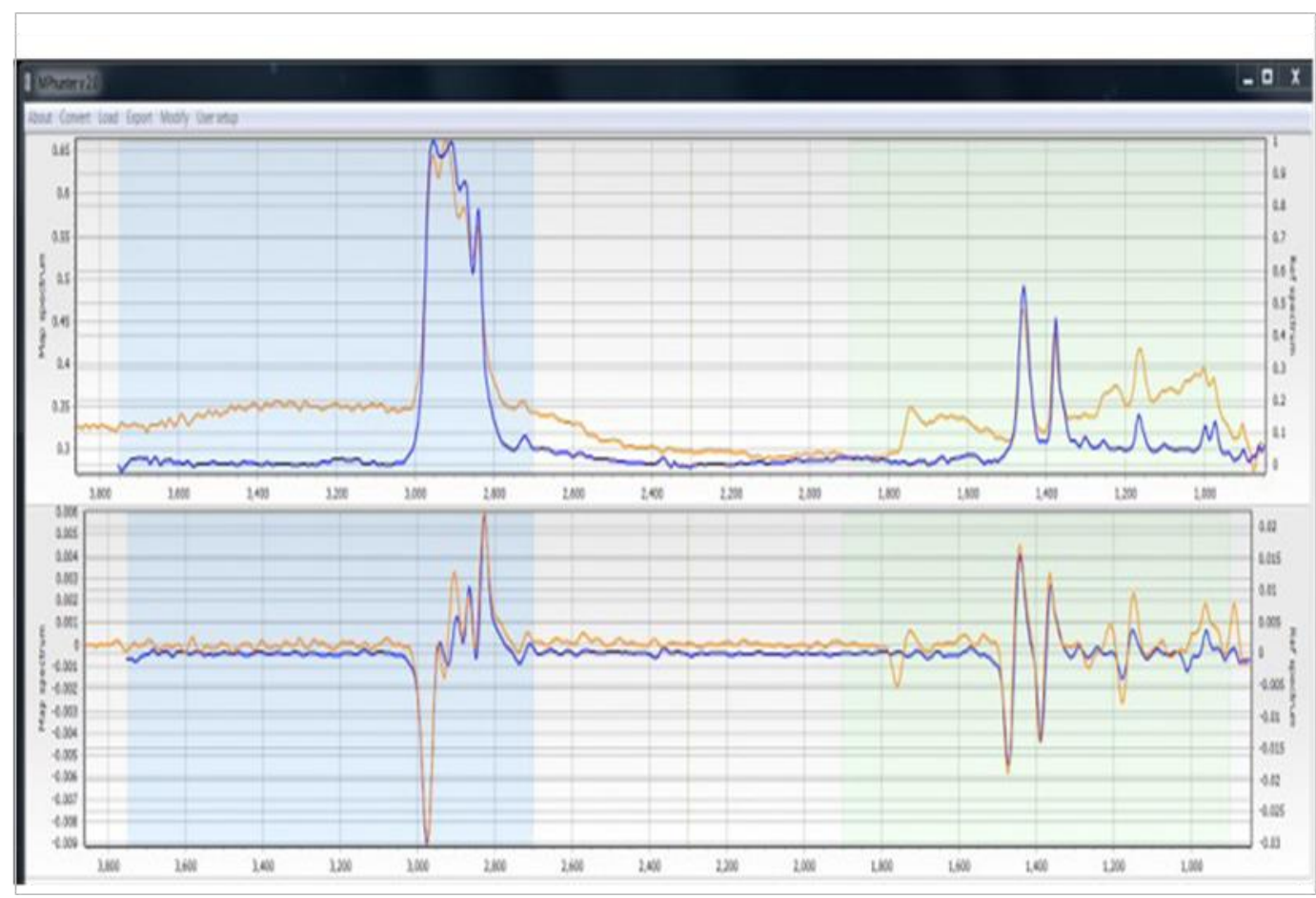

Derived spectrum

Polypropy lene spectrum

Figure 4 Screen capture of the referenced polypropylene spectrum (Blue) overlaid with an identified polypropylene spectrum (Orange).

From the data presented above, it becomes apparent that bacterial species with various catabolic potentials can act in vitro to degrade PP. The evidence emanates from contemporary weight loss of samples together with spectral analyses which indicate that the extraction products had substantial quantity of hydrocarbons as such metabolites were absent from uninoculated or cultures grown without PP. Other workers have also revealed that the formation of carbonyl and hydroxyl groups indicated intrinsic viscosity and chain scissors in PP which makes it more susceptible to biodegradation overtime [14,21,27-30]. It therefore, confirmed that bacterial attack occurred and the major bacteria involved were Bacillus lentus, B. licheniformis and Staphylococcus epidermidis. However, these organisms are different from Pseudomonas and Vibrio previously reported $[14,20]$ and such differences may arise due to geographical location and ecology of the plastisphere. 


\section{Conclusion}

The study has revealed that bacterial isolates from the internal organs (gill, intestine and tissue) of wild mullet (Liza grandisquamis) had the capacity to degrade polypropylene (PP) plastic. The order of degradation was Bacillus lentus $>$ B. licheniformis > Staphylococcus epidermidis $>$ Klebsiella pneumoniae $>$ Escherichia coli. However, further research would be needed to understand the mechanism of biodegradation of PP and the applicability of these bacteria on related synthetic polymers.

\section{Compliance with ethical standards}

\section{Acknowledgments}

Mr. Nosayame, TO is greatly appreciated for conceptualization, writing the initial draft and logistics. Our thanks also goes to Mr. Baridam, Sunebari of the Department of Microbiology, RSU, Nkpolu-Oroworukwo, Port Harcourt, Rivers State, Nigeria.

\section{Disclosure of conflict of interest}

Both authors designed the study. NTO was involved in collection of samples, laboratory work and statistical analysis. ALO supervised and wrote the article. All authors have approved the final article.

\section{References}

[1] Auta HS, Emenike CU and Fauziah SH. (2017). Distribution and importance of microplastics in the marine environment: a review of the sources, fate, effects, and potential solutions. Environ. Int, 102, 165-176.

[2] Lebreton L, Slat B, Ferrari F, Sainte-Rose B, Aitken J, Marthouse R, Hajbane S, Cunsolo S, Schwarz A, Levivier A, Noble K, Debeljak P, Maral H, Schoeneich-Argent R, Brambini R and Reisser J. (2018). Evidence that the Great Pacific Garbage Patch is rapidly accumulating plastic. Science Report, 8, 4666.

[3] Adebajo MO, Frost RL, Kloprogge JT, Carmody $O$ and Kokot S. (2003). Porous materials for oil spill cleanup: A review of synthesis and absorbing properties. J. Porous Mater, 10, 159-170.

[4] Murray ML, Poulsen SM and Murray BR. (2020). Decontaminating Terrestrial Oil Spills: A Comparative Assessment of Dog Fur, Human Hair, Peat Moss and Polypropylene Sorbents. Environments, 7(52), 2-8.

[5] Geyer R, Jambeck JR and Law KL. (2017). Production, use, and fate of all plastics ever made. Sci. Adv, 3, 1700782.

[6] Koelmans AA, Nor NHM, Hermsen E, Kooi M, Mintenig SM and De France J. (2019). Microplastics in freshwaters and drinking water: Critical review and assessment of data quality. Water Research 155, 410-422.

[7] Andrady AL. (2011). Microplastics in the marine environment. Mar. Pollut. Bull, 62, 1596-1605.

[8] Shah AA, Hasan F, Hameed A and Ahmed S. (2008). Biological degradation of plastics: A comprehensive review. Biotechnol. Adv, 26, 246-265.

[9] Malpass DB and Band EI. (2012). Introduction to polymers of propylene, in Introduction to Industrial Polypropylene: Properties, Catalysis, Processes, 1-18.

[10] Eagan JM, Xu J, Girolamo RC, Thurber CM, Macosko CW, LaPointe AM, Bates FS and Coates GW. (2017). Combining polyethylene and polypropylene: Enhanced performance with PE/ iPP multiblock polymers. Science, 355(6327), 814-816.

[11] Proshad R, Kormoker T, Islam MS, Haque MA, Rahman M and Mithu MR. (2018). Toxic effects of plastic on human health and environment: A consequence of health risk assessment in Bangladesh. Int. J Health, 6(1), 1-5.

[12] Hwang J, Choi D, Han S, Choi J and Honga J. (2019). An assessment of the toxicity of polypropylene microplastics in human derived cells. Sci. Total. Environ, 684, 657-669.

[13] Campanale C, Massarelli C, Savino I, Locaputo V and Uricchio VF. (2020). A Detailed Review Study on Potential Effects of Microplastics and Additives of Concern on Human Health. Int. J. Environ. Res. Public Health, 17, 2-26.

[14] Cacciari P, Quatrini G, Zirletta E, Mincione V, Vinciguerra P, Lupattelli P and Sermanni GG. (1993). Isotactic polypropylene biodegradation by a microbial community: Physicochemical characterization of metabolites produced, Appl Environ Microbiol, 59, 3695-3700. 
[15] Alshehrei F. (2017). Biodegradation of synthetic and natural plastic by microorganisms. J. Appl. Environ.Microbiol, 5, 8-19.

[16] Jacquin J, Cheng J, Odobe C, Pandin C, Conan P, Pujo-Pay M, Barbe V, Meistertzheim A and Ghiglione J. (2019). Microbial Ecotoxicology of Marine Plastic Debris: A Review on Colonization and Biodegradation by the "Plastisphere". Frontiers in Microbiol, 10, 865, 1-15.

[17] Montazer Z, Habibi-Najafi MB and Levin DB. (2020). Challenges with Verifying Microbial Degradation of Polyethylene. Polymers, 12, 123.

[18] Begum MA, Varalakshmi B and Umamagheswari K. (2015). Biodegradation of Polythene Bag using Bacteria Isolated from Soil. Int. J. Curr. Microbiol. App. Sci, 4(11), 674-680.

[19] Espinosa CM, Blanco AC, Schmidga T, Atanasoff-Kardjalieff AK, Kappelmeyer U, Tischler D, Pieper DH, Heipieper HJ and Eberlein C. (2020). Toward Biorecycling: Isolation of a Soil Bacterium That Grows on a Polyurethane Oligomer and Monomer. Frontiers in Microbiol, 11, 404.

[20] Arutchelvi J, Sudhakar M, Arkatkar A, Doble M, Bhaduri S and Uppara PV. (2008). Biodegradation of polyethylene and polypropylene. Indian J Biotechnology, 7, 9-22.

[21] Glaser JA. (2020). Biological Degradation of Polymers in the Environment: Chapter in: Intechopen 1-22.

[22] Rouillon C, Bussiere P, Desnoux E, Collin S, Vial C, Therias S and Gardette JL. (2016). Is carbonyl index a quantitative probe to monitor polypropylene photodegradation? Polym. Degrad. Stab, 128, 200-208.

[23] Ojha N, Pradhan N, Singh S, Barla A, Shrivastava A, Khatua P, Rai V and Bose S. (2017). Scientific Reports, 7, 39515, 1-3.

[24] Deepika S and Jaya MR. (2015). Biodegradation of low density polyethylene by microorganisms from garbage soil. J. Exp. Biol. Agricult. Sci, 3(1), 1521.

[25] Kettner MT, Oberbeckmann S, Labrenz M and Grossart H. (2019). The Eukaryotic Life on Microplastics in Brackish Ecosystems. Frontiers in Microbiology, 10, 538.

[26] Vasile C. (1993). Degradation and decomposition, in Handbook of polyolefins synthesis and properties, edited by C Vasile \& RB Seymour (Marcel Dekker Inc, New York), 479-506.

[27] Canopoli L, Coulon F and Wagland ST. (2020). Degradation of excavated polyethylene and polypropylene waste from landfill. Science of the Total Environment, 698, 134125.

[28] Pandey PJ and Singh RP. (2001). UV-Irradiated Biodegradability of Ethylene- Propylene Copolymers, LDPE, and I-PP in Composting and Culture Environments, Biomacromolecules, 2, 880-885.

[29] Alariqi SAS, Kumar AP, Rao BSm and Singh RP. (2006). Biodegradation of y-sterilised biomedical polyolefins under composting and fungal culture environments, Polymer Degradation and Stability, 91, 1105-1116.

[30] Moldovan A, Patachia S, Buican R and Tierean MH. (2012). Characterization of Polyolefins wastes by ftir spectroscopy. Bulletin of the Transilvania University of Brasov, Series I: Engineering Sciences, 5(54), 65-72. 